\title{
Orris Root Extract
}

National Cancer Institute

\section{Source}

National Cancer Institute. Orris Root Extract. NCI Thesaurus. Code C107340.

The oil extracted from the roots of Iris germanica, Iris florentina, and Iris pallida. Orris root oil is used as a perfume ingredient and as an ingredient in gin. 